\title{
CORRESPONDENCE
}

\section{EYE-DROPS IN TONOMETRY}

\section{To the Editorial Committee of the BRITISH JouRnal of OpHTHALmologY}

SIRS, - With Goldmann applanation tonometry becoming a routine investigation in eye clinics, the use of one drop containing both fluorescein and an anaesthetic agent is obviously preferable to the use of one drop of each separately. Such a drop is one containing $0 \cdot 3$ per cent. Novesine and $0 \cdot 125$ per cent. fluorescein.

The Novesine is bought as a sterile $\mathbf{0 . 4}$ per cent. solution ready for use (A. Wander Ltd.). Fluorescein is made up as a 0.5 per cent. solution to the following prescription:

$$
\begin{array}{ll}
\text { Fluorescein sodium } & 0.5 \text { per cent. } \\
\text { Phenylmercuric nitrate } & 0.004 \text { per cent. } \\
\text { Aqua dist. ad } & 100 \text { per cent. }
\end{array}
$$

Autoclave for $30 \mathrm{~min}$. at $112^{\circ} \mathrm{C} ., 10 \mathrm{lb}$. pressure.

Take one part of the fluorescein solution and three parts of Novesine and mix aseptically in a neutral glass bottle. The solution is then ready for use. One drop in each eye gives good corneal anaesthesia and a good fluorescent ring for applanation tonometry.

It will be found that the final solution contains a very slight precipitate. The precipitate is minimal and can be ignored. This is not the case when either butacaine or amethocaine is used as the anaesthetic agent for with each of these there is a heavy precipitate. Subjectively this new fluorescein-anaesthetic solution causes no more unpleasantness than the two solutions used separately, and causes less discomfort than the use of amethocaine as the anaesthetic agent.

The results of experiments using other anaesthetic agents combined with fluorescein, and the effects of sterilizing the final solution, are to be reported in the future.

I am most grateful to the Pharmacy Department of Moorfields Eye Hospital, City Road, and in particular to Miss Cynthia Horsley, for experimenting with the solutions and for dispensing them. Yours faithfully,

OphTHALmic Department,

\section{P. J. Fenton}

ST. ThOMAs's Hospital,

LONDON, S.E.1.

August 18, 1964.

\section{BOOK REVIEWS}

Vision of Children (an Optometric Symposium). Edited by M. J. HiRSCH and R. E. Wick. 1964. Pp. 434, numerous figures and tables, bibl. Hammond, London. (6 guineas).

This work is a collection of essays on various aspects of the normal and abnormal as encountered in the examination of children's eyes. As it is directed to the optometrist and optician, it is only to be expected that there is a heavy bias towards optical disorders and their treatment. The presentation of these is, on the whole, of high standard, but an ophthalmologist is bound to experience a certain lack of continuity in some chapters. This is particularly so in relation to strabismus. Much of the purely medical ophthalmology is doubtless included for the sake of reference, as well as to increase the status of the work. In this section, liberal quotation from purely ophthalmological sources is only to be expected. It is nevertheless difficult to identify the origin of the statement that retinoblastoma involves the fellow eye "by direct extension by way of the optic nerve". Probably the best part of the book is the opening chapter by the late G. L. Walls, which gives an excellent account of modern bio-genetics. This could well be read with profit and with interest by all ophthalmologists. 